Canadian

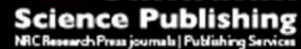

Canadian Journal of Microbiology Revue canadienne de de microbiologie

\title{
From source to filter: changes in bacterial community composition during potable water treatment
}

\begin{tabular}{|r|l|}
\hline Journal: & Canadian Journal of Microbiology \\
\hline Manuscript ID & cjm-2017-0077.R1 \\
\hline Manuscript Type: & Article \\
\hline Date Submitted by the Author: & 02-Mar-2017 \\
\hline Complete List of Authors: & $\begin{array}{l}\text { Zanacic, Enisa; SaskWater, Engineering Support \& Research } \\
\text { McMartin, Dena W.; University of Regina, Faculty of Engineering and } \\
\text { Applied Science } \\
\text { Stavrinides, John; University of Regina Faculty of Science, Department of } \\
\text { Biology }\end{array}$ \\
\hline Keyword: & biofiltration, 16S rRNA, microbial community, BAC/GAC, potable water \\
\hline & \multicolumn{2}{|c}{} \\
\hline
\end{tabular}

SCHOLARONE ${ }^{m}$

Manuscripts 
From source to filter: changes in bacterial community composition during potable water treatment

Enisa Zanacic, Dena W. McMartin, John Stavrinides

Enisa Zanacic. Engineering Support \& Research, SaskWater, Moose Jaw, Regina, Saskatchewan, Canada.

Dena W. McMartin. Faculty of Engineering and Applied Science, University of Regina, Regina, Saskatchewan, Canada.

John Stavrinides ${ }^{1}$. Department of Biology, University of Regina, Regina, Saskatchewan, Canada.

Running Head: Microbial community analysis during water treatment

${ }^{1}$ Corresponding author (e-mail: john.stavrinides@uregina.ca).

Keywords: biofiltration; 16S rRNA; microbial community; BAC/GAC; potable water; Mycobacterium; 


\begin{abstract}
Rural communities rely on surface water reservoirs for potable water. Effective removal of chemical contaminants and bacterial pathogens from these reservoirs requires an understanding of the bacterial community diversity that is present. In this study, we carried out a $16 \mathrm{~S}$ rRNAbased profiling approach to describe the bacterial consortia in the raw surface water entering the water treatment plants of two rural communities. Our results show that source water is dominated by the Proteobacteria, Bacteroidetes, and Cyanobacteria with some evidence of seasonal effects altering the predominant groups at each location. A subsequent community analysis of sections through a biological carbon filter in the water treatment plant revealed a significant increase in the proportion of Proteobacteria, Acidobacteria, Planctomycetes, and Nitrospirae relative to raw water. Also, very few enteric coliforms were identified in either the source water or within the filter, although the abundance of Mycobacterium was high, and was found throughout the filter along with Aeromonas, Legionella, and Pseudomonas. This study provides valuable insight into bacterial community composition within drinking water treatment facilities, and the importance of implementing appropriate disinfection practices to ensure safe potable water for rural communities.
\end{abstract}




\section{Introduction}

Globally, many communities rely on small surface water reservoirs as their sole water source for the production and distribution of potable water (The World Bank 2016; Bogdan and Kulshreshtha 2016; Hardie and Alasia 2009). Such reservoirs are recharged with runoff water during seasonal precipitation events as well as with spring snowmelt flow from surrounding land. The systems are open and vulnerable to environmental conditions and surrounding land use activities, making the water quality variable and sometimes unpredictable (Cessna et al. 2015; Delpla et al. 2015; Gough et al. 2016; McLeod et al. 2014). One concern is the threat posed by waterborne pathogens, such as Campylobacter, Legionella and various enteropathogenic coliforms, such as E. coli and Shigella, which can be introduced into watersheds by runoff from agricultural lands contaminated with animal wastes (Ferguson et al. 2003; Leclerc et al. 2002; World Health Organization 2011). Also of concern are chemical contaminants, including pesticides, organics, biotoxins and heavy metals, which pose a direct risk to human health (Kolpin et al. 2002). Consequently, appropriate strategies must be utilized for microbial disinfection as well as chemical contaminant remediation to ensure safe, potable water.

Ozone-assisted biofiltration systems reduce or eliminate a wide range of natural and anthropogenic and other organic pollutants in raw water by exploiting the metabolic and filtration characteristics of microorganism-derived biofilms that form on a medium of typically sand, anthracite, or granular activated carbon (GAC) (Basu et al. 2016; Gottinger et al. 2011; Liao et al. 2015; Rochex et al. 2008; Zhang et al. 2011). These filters facilitate the oxidation or biodegradation and adsorption of organics such as phenol, disinfection byproducts, pharmaceuticals, and heavy metals (Camel and Bermond 1998; Gu et al. 2016; Jang et al. 2008; Kim and Kang 2008; Niquette et al. 1998; Stackelberg et al. 2007; Ternes et al. 2002; Xiaojian et 
al. 1991; Zhang et al. 2009). In some instances, more than half of the organics present in raw water, including pesticides, sterols, flame retardants, and pharmaceuticals have been reported to be removed by GAC filters (Stackelberg et al. 2007). But, biofilter efficiency depends not only on the properties of the filter medium, such as porosity, degree of compaction, and water retention capacity, but also its capacity to host and sustain a robust microbial population that can enhance contaminant removal (Basu et al. 2016; Song et al. 2015; Srivastava and Majumder 2008). Microbial communities that establish within the filter metabolize and precipitate contaminants through biodegradation and oxidation-reduction reactions (Zhu et al. 2010), and are a function of the diversity of the community from which they are drawn, as well as substrate availability (Basu et al. 2016; Curtis and Sloan 2004; Liao et al. 2015; Liao et al. 2016). The subsequent performance of the filter communities appears to be influenced by a multitude of factors that include species richness, dynamics, evenness, and functional redundancy of the bacterial community (Basu et al. 2016; Boon et al. 2011; Briones and Raskin 2003; Fish et al. 2015), making an understanding of the composition and interplay of microbial communities in source water, as well as within biofilters essential for enhancing drinking water treatment and water source management.

Recent analyses examining influent, effluent and biofilters of drinking water treatment facilities have yielded new insight into the predominant microbial communities influencing drinking water remediation. A 15-month survey of the bacterial communities in a water treatment plant (WTP) and corresponding distribution system in Michigan revealed that the Alpha-, Beta-, and Gammaproteobacteria predominated, along with candidate phylum OD1 (Candidatus Parcubacteria) (Harris et al. 2004; Pinto et al. 2014). Betaproteobacteria dominated during the summer months while Alphaproteobacteria dominated in winter, with Acidovorax 
being a dominant Betaproteobacterial group (Pinto et al. 2014). Bacterial community structure correlated with various water quality parameters, including $\mathrm{pH}$, ammonium, sulfate, phosphate, and carbon concentrations, which in turn, were correlated with season (Pinto et al. 2014). These results were consistent with another microbial survey of a WTP in Australia, which evaluated microbial diversity at different stages along the treatment train (Shaw et al. 2015). This work showed that bacterial consortia were altered after disinfection, suggesting treatment was effective, although several bacterial groups known to contain pathogenic species were identified in samples containing high concentrations of disinfectant (Shaw et al. 2015). A further analysis revealed that bacteria colonizing the biofilter were composed of predominantly Alphaproteobacteria, Betaproteobacteria, Bacteroidetes, and Actinobacteria, with Acidovorax, Hydrogenophaga, and Denitratisoma being found throughout the system, both pre- and postdisinfection (Shaw et al. 2015). The filter communities were shown to be strongly correlated with water $\mathrm{pH}$, and to a lesser extent, carbon and phosphorus (Shaw et al. 2015). Notably, some effluent samples were shown to be more similar to source water than to post-disinfection water, suggesting that microbial repopulation of water occurred later within the distribution system (Shaw et al. 2015). This not only reinforces the importance of maintaining disinfectant residuals throughout the system, but also reinforces the importance of understanding microbial community composition given that nitrifying bacteria like Nitrosomonas may metabolize monochloroamine disinfectants and reduce residuals (Berry et al. 2006; Maestre et al. 2013). Thus, a fundamental understanding of bacterial community dynamics of these systems, including the links between filter communities and source water allows for enhanced oversight and optimization of filter efficiency for the production of safer, potable water. 
In this study, we used $16 \mathrm{~S}$ rRNA profiling to describe the bacterial communities of water entering the drinking water treatment plants of the village of Osage and the hamlet of Benson in rural Saskatchewan, both of which use surface water as their water source. We show that the bacterial consortia in each water source are compositionally distinct, and that the predominant bacterial groups change with seasonality. A further evaluation of the microbial communities in three transects within a biological activated carbon (BAC) filter revealed a dramatic shift in community composition from raw water, and that Legionella, Pseudomonas, Aeromonas, and especially Mycobacterium established within the filter. Our work suggests that BAC filters may provide a suitable niche favouring the accumulation of some bacteria, making disinfection postfiltration, and the maintenance of disinfectant residuals throughout the distribution system critical to ensuring safe potable water for rural communities.

\section{Materials and Methods}

Study Sites

Two small rural communities, the village of Osage (population 20) and the Hamlet of Benson (population 95), have potable water treatment plants whose ozone-assisted biofiltration systems were underperforming according to operating specifications. These communities are home to the longest running and provincially regulated ozone-assisted biofiltration plants in the province. The Osage WTP has a design flow rate of $11 \mathrm{~m}^{3} /$ day and includes one $0.66 \mathrm{~m}$ diameter roughing filter, one $1.75 \mathrm{~m}$ diameter biological sand filter and one $1 \mathrm{~m}$ diameter BAC filter (Zanacic et al. 2016). A re-circulation system recycles non-chlorinated water at $0.6 \mathrm{~m}^{3} / \mathrm{hr}$ through the BAC filter to increase aeration. Treated water is then chlorinated and stored in a storage tanks prior to distribution. Two ozone generators (VMUS-04) provide an ozone dosage of $4 \mathrm{~g} / \mathrm{hr}$ at $5 \mathrm{~L} / \mathrm{min}$ airflow and $7 \mathrm{mg} / \mathrm{L}$ at average flow rate. Thus, the applied ozone dose is 
approximately $17 \mathrm{mg} / \mathrm{L}$ (Zanacic et al. 2016). An air dryer was installed in April 2012 to improve the efficiency of the ozone generator.

The Benson WTP is designed to provide potable water at a rate of $45 \mathrm{~m}^{3} /$ day and includes one $1.5 \mathrm{~m}$ diameter roughing filter, two $2.1 \mathrm{~m}$ diameter biological sand filters and two $2.1 \mathrm{~m}$ diameter BAC filters (Zanacic et al. 2016). Much like the Osage WTP design, aeration of BAC filters in enabled by a re-circulation system that recycles non-chlorinated water back into BAC filters at $0.6 \mathrm{~m}^{3} / \mathrm{hr}$. Treated water is chlorinated and stored in tanks prior to distribution. Four ozone generators (VMUS-04) are each capable of generating up to $7 \mathrm{mg} / \mathrm{L}$ of ozone per unit at 6 $\mathrm{L} / \mathrm{min}$ of oxygen resulting in a full operating capacity ozone dose of $17 \mathrm{mg} / \mathrm{L}$ (Zanacic et al. 2016).

\section{Sample Collection and DNA extraction}

Raw water samples were collected from surface water reservoirs in $1 \mathrm{~L}$ plastic bottles in both communities in fall (September) 2012 and spring (March/April) 2013. Approximately 0.35 L of raw water samples were vacuum filtered using $0.2 \mu \mathrm{m}$ Millipore filters (GSWP04700).

Filter discs were placed in a conical tube, $35 \mathrm{~mL}$ of raw water added, and the mixture vortexed to re-suspend the sediments/turbidity particles collected on the filter. The filter paper was removed from the conical tube, and the suspensions centrifuged at $186 \mathrm{x} g$ for 10 minutes. The resulting pellet was recovered and processed using the MoBio PowerSoil® kit (Mo Bio, California), as per the manufacturer's instructions.

BAC filter samples were collected using a grain coring tool approximately eight (8) inches from the centre of the filter and at three depths within the BAC filter (top $1 / 3$, middle $1 / 3$ and bottom 1/3) at the Osage WTP in the fall. Samples were placed in sterile bottles, $50 \mathrm{~mL}$ of 
distilled water added, and samples vortexed for 10 minutes to dislodge microbes from the BAC medium. Suspensions were then centrifuged, and DNA extracted from the sample pellet using the MoBio PowerSoil ${ }^{\circledR}$ DNA Isolation Kit (Mo Bio, California, USA) as per the manufacturer's instructions.

$16 S$ rRNA amplification

Amplification of the V4 region of the $16 \mathrm{~S}$ rRNA was carried out in $50 \mu \mathrm{L}$ PCR reactions containing 1 unit of Phusion DNA polymerase (2 U/ $\mu \mathrm{L})$ (New England Biolabs, Massachusetts, USA) $10 \mu \mathrm{L}$ of $5 \mathrm{x}$ HF buffer, $0.25 \mu \mathrm{L}$ of the $515 \mathrm{~F} 16 \mathrm{~S}$ rRNA primer $(100 \mu \mathrm{M})$ and $0.25 \mu \mathrm{L}$ of the 806R 16S rRNA primer $(100 \mu \mathrm{M})$ containing a unique barcode for multiplexing, $0.40 \mu \mathrm{L} 10$ $\mathrm{mM}$ dNTP and approximately $10 \mathrm{ng}$ of template DNA. Three PCR amplifications were prepared for each sample, and subsequently pooled. Cycling conditions were as follows: one cycle of $98^{\circ} \mathrm{C}$ for $2 \mathrm{~min}$, followed by $98^{\circ} \mathrm{C} / 10 \mathrm{sec}, 50^{\circ} \mathrm{C} / 30 \mathrm{sec}, 72^{\circ} \mathrm{C} / 15 \mathrm{sec}$ ) for $20 \mathrm{cycles}$, followed by a final polymerization step of $72^{\circ} \mathrm{C}$ for $7 \mathrm{sec}$ (Bartram et al. 2011). Samples were visualized following separation with gel electrophoresis, and amplicons purified using the E.Z.N.A. Gel Extraction Kit (Omega Bio-Tek, Georgia, USA). The concentration and purity of samples were confirmed by NanoDrop UV-Vis Spectrophotometer. Sequencing of amplicons was carried out on an Illumina GAIIx platform by McGill University and Génome Québec Innovation Centre (Montréal, Quebec, Canada). Datasets are available under MG-RAST accession/project numbers (4528546, 4528547, 4528548, 4528549, 4528550, 4528553 and 4528554). Summary statistics for these datasets are available in Table S1.

Microbial Community Analyses 
Reads were processed with MG-RAST (Meyer et al. 2008) to remove eukaryotic contamination, and the resulting reads that passed quality control were subsequently analyzed, clustered, and classified using the RDPipeline using a cutoff of $80 \%$ and $16 \mathrm{~S}$ copy number correction (Cole et al. 2014; Wang et al. 2007). The RDPipeline was also used to calculate alpha diversity (Shannon Index) at a distance of 0.03 , and to generate rarefaction curves at a distance of 0.03 . Analyses of significant differences between taxonomic abundances of two samples (including unclassified reads) were conducted with STAMP, using two-sided G-test (with Yates') + Fisher's and Storey-FDR multiple-test correction (Parks and Beiko 2010).

\section{Results}

\section{Microbial Diversity}

The microbial composition of surface water from the reservoirs of Osage and Benson was evaluated in both fall and spring using 16S rRNA amplicon sequencing. Approximately 5-15\% of the representative reads for the four samples could not be classified to the level of domain, although 50-70\% were assigned at least to the level of phylum within either the Bacteria or the Archaea (Figure 1A). The Shannon Diversity Index for all four raw water samples ranged from 7.33 to 7.96 (Table S1; Figure 2). The Proteobacteria dominated both sites in both seasons, accounting for $20-30 \%$ of overall diversity (Figure 1B), with the Betaproteobacteria making up the majority (30-55\%), followed by the Alphaproteobacteria (20-30\%), Gammaproteobacteria (15-20\%), and Deltaproteobacteria (10-20\%) (Figure 1C). A further evaluation of the identifiable genera within these phyla showed that one genus, Polynucleobacter (Betaproteobacteria), was present across both sites in both seasons, reaching almost $7 \%$ in Benson in the spring. In contrast, other groups correlated with season, such as the 
Betaproteobacterial groups, Polaromonas (1.4-1.7\%) and Rhodoferax (0.5\%), which were higher in the spring (Figure 2).

The Cyanobacteria/Chloroplast group was also well-represented across all four samples, but had higher representation in water collected from Osage in both the fall and spring (almost $20 \%$ ) than in Benson (15\% and 6\%) (Figure 1), with the majority of the Benson cyanobacterial and/or chloroplast sequences being derived from the eukaryotic groups, Bacillariophyta, Cryptomonadaceae, and Chlorophyta (Figure 2). In contrast, 16-17\% of the Cyanobacteria/Chloroplast group represented at Osage were derived from the above eukaryotic groups, with the remainder being composed of Group I Cyanobacteria, including Aphanizomenon, Anabaena, and Anabaenopsis, as well as the Group IIa genera, Cyanobium, Microcystis and Synechococcus. The Bacteroidetes accounted for $8-12 \%$ of the overall sample diversity across both sites in both seasons, with a greater abundance in Benson (12\%) than at Osage (8\%)(Figure 1). One of the more predominant Bacteroidetes genera common to both sites in both seasons was Flavobacterium (0.6-0.8\%), while Pedobacter (0.5-0.7\%) was more abundant in the spring at both sites. The Actinobacteria increased from around 3\% in the fall to $8 \%$ in the spring at both Osage and Benson (Figure 1), with the predominant spring taxon being Mycobacterium (0.8-1.1\%) (Figure 2). The Bacteroidetes, Proteobacteria, and Cyanobacteria, together with the Verrucomicrobia (4-7\%), Actinobacteria (3-9\%), Planctomycetes (3-7\%), and Acidobacteria (2-3\%) accounted for more than $90 \%$ of the taxonomically-defined diversity at both sites and in both seasons. A temporal (season-specific) analysis showed that the Actinobacteria, Proteobacteria, and Verrucomicrobia were always significantly higher in the spring, independent of the site (1-6\% difference in proportions, G-test, $\mathrm{p}<10^{-4}$ ) (Figure $\left.3 \mathrm{~A}\right)$. A spatial (site-specific) analysis of the relative abundance of the different phyla revealed that the 
Bacterioidetes and Proteobacteria were higher at Benson than at Osage in both seasons (3-6\% difference in proportions, G-test, $\mathrm{p}<10^{-4}$ ), while Cyanobacteria were significantly higher at Osage than at Benson (3-10\% difference in proportions, G-test, $\mathrm{p}<10^{-15}$ ) (Figure 3B). The phyla exhibiting large spatial and temporal differentials are summarized in Figure 3C.

Given the central role of water treatment in reducing waterborne bacterial pathogens, we evaluated the presence of pathogens and toxin-producing bacteria in raw water entering both treatment plants. Of particular concern are those organisms often associated with human disease, including species of Burkholderia, Campylobacter, Escherichia/Shigella, Legionella, Leptospira, Mycobacterium, Salmonella, and Vibrio (Ferguson et al. 2003; Leclerc et al. 2002; World Health Organization 2011), although we also surveyed for the presence of several other genera that are commonly associated with water reservoirs, including Acinetobacter, Aeromonas, Helicobacter, Pseudomonas, and Staphylococcus, as well as the enteric coliforms, Enterobacter, Klebsiella, Cronobacter, Serratia, and Yersinia (World Health Organization 2011). Acinetobacter, Yersinia, and Leptospira were at extremely low abundance in most samples $(<0.02 \%)$, while Aeromonas and Pseudomonas reached up to $0.1 \%$ in some samples. In contrast, Mycobacterium was more abundant in both spring samples at both sites, being found at $1.1 \%$ at Osage and $0.8 \%$ at Benson (Figure 2). In the fall, it was found at only around $0.2-0.3 \%$ at both sites. We extended our search to a broader range of taxa that contain pathogenic species, and noted the presence of Staphylococcus and Clostridium, although these were also at extremely low levels $(<0.01 \%)$.

\section{Microbial community composition of the BAC filter}

To evaluate changes in microbial community composition through the BAC filter, a sample core was taken from the Osage BAC filter in the fall, split into three (top, middle, 
bottom), and microbial diversity assessed on each fraction. Comparisons of community composition in the filter were made to the Osage Fall sample, which served as the source raw water entering the filter. Approximately $95 \%$ of sequences from the three BAC samples were assigned to the Bacteria or Archaea, with approximately 5\% being unclassified (Figure 1A). Of the sequences classified to either the Bacteria or Archaea, approximately 35-40\% could not be classified to phylum (Figure 1B). Of the sequences that could be classified, members of the Proteobacteria comprised the majority of dominant taxa throughout the BAC filter at approximately $23 \%$ (Figure $1 \mathrm{~B}$ ), decreasing in proportion with increased depth. Of the Proteobacterial classes represented, Alpha (23-30\%), Delta (21-25\%), and Betaproteobacteria (21\%) were more abundant throughout the filter than the Gammaproteobacteria $(15-17 \%)$ (Figure 1C). Some of the predominant Proteobacterial genera included Arenimonas, Thiothrix, and Thiobacillus $(0.6-0.7 \%)$, all of which were more abundant in the top fraction, along with Bdellivibrio, which was found at approximately $0.4 \%$ throughout the three layers (Table 1 ). One member of the Proteobacteria, Polynucleobacter, which was found at $1.5 \%$ in raw water was reduced to $0.2-0.4 \%$ in the filter (Table 1$)$.

Members of the Planctomycetes and Acidobacteria were significantly overrepresented in the filter as compared to raw water entering the filter $(12-15 \%$ versus $4 \%$, G-test, $\mathrm{p}<\mathrm{e}-15)$ (Figure 3D), and both showed a trend of increasing abundance with increasing depth (Figure 1B). The Planctomycete, Pirellula, increased from $0.6 \%$ in raw water to as high as $3 \%$ in the filter, while Group 6 of the Acidobacteria, increased from 1\% in the raw water to as high as $4 \%$ in the filter (Table 1). Many other groups of the Acidobacteria, including Gp4, Gp16, Gp3, Gp7, and Gp10 were all represented throughout the filter, each at an abundance of $>0.3 \%$. Similarly, the Nitrospirae made up a significantly larger proportion of the filter community as compared to 
raw water (1\% versus 5-7\%, G-test, $\mathrm{p}<\mathrm{e}-15)($ Figure 3D), with Nitrospora, a known nitrifier (Lucker et al. 2010) increasing to up to 7\% within the filter (Table 1). Other groups represented within the filter in relatively higher proportions included Gemmatimonas (Gemmatimonadetes) $(\sim 1 \%)$, members that have been reported accumulate polyphosphate (Zhang et al. 2003), the Group 5 in the Armatimonadetes (0.6\%)(Lee et al. 2013), and both Candidatus groups in the Verrucomicrobia, Subdivision $3(\sim 0.6 \%)$ and Spartobacteria $(\sim 0.4 \%)$ (Table 1). Among the less studied and more ambiguous taxa that increased in the filter included the genus Litorilinea (up to 0.4\%) from the Chloroflexi, representatives from the two candidate phyla, WPS-1 $(0.3 \%)$, and Saccharibacteria $(0.3 \%)$, and even representatives of AR13 from the recently proposed Archaeal phylum, Pacearcheaota $(\sim 0.3 \%)$ (Castelle et al. 2015). In contrast, several groups were reduced significantly within the filter relative to raw water, including the Group I (Aphanizomenon, Anabaena, and Anabaenopsis) and Group IIa (Cyanobium, Microcystis and Synechococcus) Cyanobacteria, which were reduced from $0.7-1.5 \%$ to $<0.4 \%$ in the filter (Figure 3D). Similarly, the eukaryotic (chloroplast) groups, Cryptomonadaceae, Bacillariophyta, and Chlorophyta, which together comprised about $15 \%$ of the raw water diversity were reduced to approximately $1 \%$, on average, throughout the filter (Figure 3D).

\section{Assessment of potential pathogens in the BAC filter}

Given that the raw water samples, including the Osage spring sample contained some bacterial groups with human pathogenic potential, we attempted to assess the fate of these bacteria within the filter. Many of the waterborne pathogens that are of greatest concern, including most of the enteric coliforms such as E. coli, Yersinia, Serratia, Salmonella, Enterobacter, and Klebsiella, which were largely absent from raw water were also at negligible densities within the filter. Legionella, which was found at approximately $0.02 \%$ in raw water 
remained at approximately this concentration throughout the different filter fractions, while Pseudomonas and Aeromonas, which were each present at approximately $0.1 \%$ in raw water were reduced to approximately $0.02 \%$ (Figure 4). In contrast, Mycobacterium, which was at approximately $0.15 \%$ in raw water, increased slightly to $0.2-0.3 \%$ in the filter (Table 1 ; Figure 4).

\section{Discussion}

In this study, we used $16 \mathrm{~S}$ rRNA profiling to assess the microbial communities found in surface water reservoirs that feed into the WTPs of two rural sites. In addition, we examined how these bacterial communities relate to microbial diversity within three transects of a BAC filter localized within one of those WTPs. Our sequencing depth of the different samples varied, despite our consistent sampling and processing methods (Table S1; Figure S1). Of the sample reads, around $25-35 \%$ of sequence reads could only be assigned to domain (Figure 1), reflecting the considerable gap in our understanding of bacterial diversity. In addition, several of our raw water samples had eukaryotic DNA contamination, and more specifically chloroplast rRNA, likely from the highly abundant diatoms and phytoplankton in our water samples.

An evaluation of bacterial community composition at the level of phylum at the two sites revealed several spatial and temporal differences in microbial diversity and distribution. The abundance of Cyanobacteria, Bacteroidetes and Proteobacteria appeared to correlate with location, with former being more abundant at Osage, and the latter two more abundant at Benson, irrespective of season. The higher abundance of Cyanobacteria at Osage is particularly noteworthy, given that strains of Anabaena, Aphanizomenon, Cylindrospermopsis, Lyngbya, Microcystis, Nodularia, Nostoc, Oscillatoria, Planktothrix, Raphidiopsis, and Umezakia produce 
a variety of anatoxins, saxitoxins, microcystins, and cylindrospermopsins (Carmichael 2001; Lyra et al. 2001; Neilan et al. 1999; World Health Organization 2011). Aphanizomenon, Anabaena, Anabaenopsis, and Microcystis were identified in raw water samples, some species of which produce hepatotoxins and neurotoxins such as cylindrospermopsin, saxitoxin and anatoxin-A (Carmichael 2001; Lyra et al. 2001). Because these Cyanobacteria were not as abundant at Benson, it could suggest differences in the availability of limiting micro- and macronutrients (Elser et al. 2007), although other factors, such as turbidity, can also reduce solar light penetration through the water column, thereby limiting growth of these autotrophs. The Osage reservoir is shallower and contained lower dissolved organic carbon at sampling $(\sim 12$ $\mathrm{mg} / \mathrm{L})$ than did the Benson reservoir ( $30 \mathrm{mg} / \mathrm{L})$ (Zanacic et al. 2016), possibly favouring more light penetration. Paradoxically, throughout the year, nitrogen levels at Benson ranged from 2.4$3.9 \mathrm{mg} / \mathrm{L}$, about two times those of Osage (1.0-1.8 mg/L) while phosphorus levels at Benson were around $0.2-1.3 \mathrm{mg} / \mathrm{L}$, also slightly higher than those found at Osage $(0.4-0.8 \mathrm{mg} / \mathrm{L})$ (Zanacic et al. 2016). This could suggest alternative environmental factors impacting cyanobacterial abundance, such as the presence of bacteriophage that may have caused the prevailing cyanobacterial populations to collapse. This was noted in one freshwater environment, where not only did cyanobacterial population collapse due to bacteriophage, but this caused the increased the population of Actinomycetes, as well as some members of the Bacteroidetes (van Hannen et al. 1999). The greater abundance of the Bacteroidetes at Benson is consistent with this finding, and could reflect an increase in the availability of nutrition due to lysis of predominant cyanobacterial populations, which is also supported by the slight increase in measured DOC from the fall (30.4 mg/L) to the spring (35.6 mg/L) (Zanacic et al. 2016). 
The abundance of several phyla changed temporally (with season), including the Actinobacteria, Proteobacteria, and Verrucomicrobia, all three of which were higher in the spring at both Osage and Benson. The Proteobacteria, whose abundance we found also correlated with site (higher in Benson samples), has been previously suggested to remain prevalent throughout the season (60-70\% of the community) (Pinto et al. 2014), with some studies demonstrating that the Alphaproteobacteria class is more abundant in the winter, and the Betaproteobacteria class in the summer (McCoy and VanBriesen 2012). Partially consistent with this, our results show that the Betaproteobacteria are higher in the spring at both sites, whereas the Gammaproteobacteria are higher in the fall at both sites. In addition, our results were also consistent with reports that the Proteobacterial communities, as well as the Actinobacteria may occupy specific temporal niches within aquatic environments, oscillating between seasons depending on the availability of various nutrients (Glockner et al. 2000). Because many pathogenic bacterial groups fall within the Proteobacteria, identifying any seasonal effects on the prevalence of these groups has important implications for disinfection practices and management within WTPs.

The BAC filter plays a central role in the biodegradation and adsorption of dissolved organic carbon and disinfection byproducts, as well as the nitrification of ammonia (Kim and Kang 2008; Niquette et al. 1998; Xiaojian et al. 1991). We noted very similar proportions of unclassified bacteria in the Osage filter (37-39\%), which were slightly higher than those in the raw water samples (Figure 1A), suggesting an as-yet unknown community diversity that may drive biofilter activity and efficiency. This may also be a reflection of niche-specific colonization of the BAC by specific unclassified groups, which is supported by the increase in the relative proportion of the unclassified Proteobacteria in the filter (Figure 1B), as well as the 
overall dramatic shift in microbial community composition as compared to the raw water samples. For example, the Alphaproteobacteria and Deltaproteobacteria increased in the filter relative to raw water, while the Betaproteobacteria decreased. Although the Betaproteobacteria decreased, they still comprised $20 \%$ of the diversity, which has been suggested to be due to the diverse metabolic capabilities of this group (Kaarela et al. 2015; Niemi et al. 2009). We also found that the higher abundance of Deltaproteobacteria, which made up a higher proportion in the filter, and which decreased with increasing depth, was consistent with the diverse metabolic capabilities of its many anaerobic members, such as the metal-reducing Anaeromyxobacter and Geobacter, as well as the sulfur- and sulfate-reducing anaerobic members within the Desulfobacterales (Barton and Fauque 2009; Castro et al. 2000). We noted the greater proportion of Bdellovibrio within the filter, a predatory group within the Deltaproteobacteria (Rendulic et al. 2004; Stolp and Starr 1963), which may be serving to alter community composition.

One of the other obvious shifts in filter composition was the striking increase in the Planctomycetes, Acidobacteria, and Nitrospirae in the filter, relative to raw water. The most abundant taxa within these phyla were Nitrospora (Nitrospirae), Gp6 (Acidobacteria), and Pirellula (Planctomycetes), all three of which were consistent throughout the filter layers. Many of these groups have been suggested to play important roles in nutrient cycling in a variety of environments (Fierer et al. 2007; Lucker et al. 2010; Strous et al. 2006). Nitrospira, for example, which are nitrifying bacteria that transform ammonia to nitrate (Lucker et al. 2010), shifted from $1.1 \%$ in raw water to $7 \%$ in the bottom of the BAC filter, indicating a possible prominent ecological role within the filter. Nitrospora spp. were also found to be abundant in several other studies evaluating microbial diversity across various stages of drinking water treatment (Kaarela 
et al. 2015; Pinto et al. 2012; Shaw et al. 2015; Yapsakli et al. 2010), but it is important to note that the metabolic activities of nitrifying bacteria, including Nitrosomonas that was also identified within the Osage BAC filter, have been shown to decrease disinfectant residuals of chloroamines (Berry et al. 2006; Maestre et al. 2013, 2016). It is therefore important to actively monitor disinfectant residuals to ensure they are not being rapidly degraded by these microbes.

The Planctomycete, Pirellula, and Gp6 (subdivision 6) of the Acidobacteria, increased from less than one percent in raw water to around $3 \%$ in the filter, and therefore make up a decent proportion of this BAC bacterial community. Representative strains of Pirellula use a wide variety of carbon sources and can produce $\mathrm{H}_{2} \mathrm{~S}$ from thiosulfate (Clum et al. 2009). They have been identified as members of communities involved in alcohol manufacturing wastewater treatment plants (Yang et al. 2007), further reinforcing their role in nutrient cycling. A recent genomic analysis of one representative of Gp6 (subdivision 6) of the Acidobacteria revealed a diversity of predicted metabolic functions, including nitrate and sulfite reduction, as well as genetic determinants for arsenate, arsenite, antimonite, cobalt, zinc, lead, cadmium, and mercury detoxification (Huang et al. 2016). Other subdivisions of the Acidobacteria, including Gp4, Gp16, Gp3, Gp7, and Gp10, also increased within the filter, indicating that the biology of these groups may be important for understanding biofilter function.

Because BAC filters are readily colonized by a diversity of microbes, we were interested in the fate of pathogens and cyanobacteria within the filter. We found that Cyanobacteria in the Osage raw water, which accounted for approximately $2 \%$ of the diversity, were barely detectable in any transect of the Osage BAC filter, suggesting they are being reduced to negligible numbers. This was also true of several groups within the Flavobacteria (Bacteroidetes) (Table 1). Furthermore, we noted that many of the waterborne pathogens of greatest concern, including 
E.coli/Shigella, Salmonella, Campylobacter, and Vibrio were not as abundant in the source water at either site, and were also not identified in the filter at any notable concentration. This was somewhat surprising given that fecal coliforms, as well as bacteria normally found in gut of animals, such as Campylobacter, are often expected be more prevalent in areas like Osage and Benson where animals pasture in fields and surrounding plots (Huang et al. 2015; Wilkes et al. 2011). Other genera that include potentially pathogenic species, like Pseudomonas and Aeromonas, were found in raw water, but were reduced to $<0.05 \%$ in the filter. The particular species representing these two genera could not be identified with any confidence, although previous work has suggested that some pathogenic species that carry virulence factors, such as those of Aeromonas, can persist in municipally treated water (Sen and Rodgers 2004). Likewise, Legionella, which was identified in raw water, persisted within the filter, albeit at a relatively low abundance $(0.02 \%)$. Legionella is an intracellular pathogen, which has been reported to be a natural colonizer of GAC (Wang et al. 2013), and which can persist through water treatment systems within amoebae, such as Acanthamoeba (Thomas et al. 2008). This has also been demonstrated for species of Mycobacterium, which in our study increased from about $0.15 \%$ in raw water to around $0.3 \%$ in the filter (Table 1). Like Legionella, species of Mycobacterium are natural colonizers of BAC (Wang et al. 2013), can survive within amoebae (Thomas et al. 2008), and have been identified as a prevalent microbe in both experimental and treatment plant filters and distribution systems (Dailloux et al. 2003; Revetta et al. 2013; Revetta et al. 2016; Stanish et al. 2016; Thomas et al. 2008; Wang et al. 2013). Species of Mycobacterium are of particular concern for drinking water safety, given that they are the causal agent of human and animal tuberculosis, as well as a variety of other respiratory infections in both healthy and immunocompromised individuals (Wagner and Young 2004). Given that backwashing is 
important for management of bacterial biomass and proper filter performance (Urfer et al. 1997), the recommended backwash frequency for the Osage BAC filter is every 4 to 5 months (Zanacic et al. 2016), which may also help to purge pathogen populations.

Although Benson and Osage have similar water sources (surface water reservoirs) recharged by runoff from agricultural fields where similar cropping and cultivation systems are applied in the same climatic region, the microbial diversity and composition are different. The proportion of Cyanobacteria was higher in Osage samples, while Proteobacteria and Bacteroidetes were greater in Benson samples. The Proteobacteria, Actinobacteria, and Verrucomicrobia showed a temporal effect, increasing in the spring at both sites. We also found that community composition of the BAC filter shifted relative to raw water, with a distinctive increase in the proportion of Proteobacteria, Acidobacteria, Planctomycetes, and Nitrospirae, and a decrease in the Bacteroidetes and Cyanobacteria/Chloroplast groups. The BAC filter contained populations of Legionella, Aeromonas, Pseudomonas and Mycobacterium, with proportions of the latter remaining consistent throughout the filter media. This has implications for ensuring low titres of pathogens in the distribution system using disinfection residuals, with the caveat that nitrifiers identified within the BAC filter may be contributing to the degradation of monochloroamine compounds used for disinfection. The concentration of potentially pathogenic groups within the filter reinforces the vital importance of post-filter disinfection practices and active monitoring to ensure disinfection residuals are maintained throughout the treatment process.

\section{Acknowledgments}


The authors thank Sam Ferris, Executive Director, Environmental and Municipal Services at the Water Security Agency of Saskatchewan, as well as the Saskatchewan Ministry of Environment for both in-kind and direct financial support. The authors also gratefully acknowledge financial support from the Natural Sciences and Engineering Research Council of Canada to McMartin (288137-15) and Stavrinides (386654-10), and the Canada Foundation for Innovation to Stavrinides (28591).

\section{References}

Barton, L.L., and Fauque, G.D. 2009. Biochemistry, physiology and biotechnology of sulfatereducing bacteria. Adv. Appl. Microbiol. 68: 41-98. doi: 10.1016/s0065-2164(09)01202-7.

Bartram, A.K., Lynch, M.D., Stearns, J.C., Moreno-Hagelsieb, G., and Neufeld, J.D. 2011. Generation of multimillion-sequence 16S rRNA gene libraries from complex microbial communities by assembling paired-end illumina reads. Appl. Environ. Microbiol. 77(11): 3846-3852. doi: 10.1128/aem.02772-10.

Basu, O.D., Dhawan, S., and Black, K. 2016. Applications of biofiltration in drinking water treatment - a review. Journal of Chemical Technology \& Biotechnology 91(3): 585-595. doi: $10.1002 /$ jctb. 4860 .

Berry, D., Xi, C., and Raskin, L. 2006. Microbial ecology of drinking water distribution systems. Curr. Opin. Biotechnol. 17(3): 297-302. doi: 10.1016/j.copbio.2006.05.007. 
Bogdan, A.M., and Kulshreshtha, S. 2016. Temporal and spatial scale community level water use in Saskatchewan. Journal of Aquaculture Research \& Development 07(02). doi: $10.4172 / 2155-9546.1000404$.

Boon, N., Pycke, B.F., Marzorati, M., and Hammes, F. 2011. Nutrient gradients in a granular activated carbon biofilter drives bacterial community organization and dynamics. Water Res. 45(19): 6355-6361. doi: 10.1016/j.watres.2011.09.016.

Briones, A., and Raskin, L. 2003. Diversity and dynamics of microbial communities in engineered environments and their implications for process stability. Curr. Opin. Biotechnol. 14(3): $270-276$.

Camel, V., and Bermond, A. 1998. The use of ozone and associated oxidation processes in drinking water treatment. Water Res. 32(11): 3208-3222. doi: 10.1016/s0043-1354(98)001304.

Carmichael, W.W. 2001. Health effects of toxin-producing cyanobacteria: "The cyanohabs". Human and Ecological Risk Assessment: An International Journal 7(5): 1393-1407. doi: $10.1080 / 20018091095087$.

Castelle, Cindy J., Wrighton, Kelly C., Thomas, Brian C., Hug, Laura A., Brown, Christopher T., Wilkins, Michael J., Frischkorn, Kyle R., Tringe, Susannah G., Singh, A., Markillie, Lye M., Taylor, Ronald C., Williams, Kenneth H., and Banfield, Jillian F. 2015. Genomic expansion of domain archaea highlights roles for organisms from new phyla in anaerobic carbon cycling. Curr. Biol. 25(6): 690-701. doi: 10.1016/j.cub.2015.01.014.

Castro, H.F., Williams, N.H., and Ogram, A. 2000. Phylogeny of sulfate-reducing bacteria. FEMS Microbiol. Ecol. 31(1): 1-9. doi: 10.1016/S0168-6496(99)00071-9. 
Cessna, A.J., Donald, D.B., Bailey, J., and Waiser, M. 2015. Persistence of the sulfonylurea herbicides sulfosulfuron, rimsulfuron, and nicosulfuron in farm dugouts (ponds). Journal of Environmental Quality 44(6): 1948-1955. doi: 10.2134/jeq2014.11.0503.

Clum, A., Tindall, B.J., Sikorski, J., Ivanova, N., Mavrommatis, K., Lucas, S., Glavina, T., Del, R., Nolan, M., Chen, F., Tice, H., Pitluck, S., Cheng, J.-F., Chertkov, O., Brettin, T., Han, C., Detter, J.C., Kuske, C., Bruce, D., Goodwin, L., Ovchinikova, G., Pati, A., Mikhailova, N., Chen, A., Palaniappan, K., Land, M., Hauser, L., Chang, Y.-J., Jeffries, C.D., Chain, P., Rohde, M., Göker, M., Bristow, J., Eisen, J.A., Markowitz, V., Hugenholtz, P., Kyrpides, N.C., Klenk, H.-P., and Lapidus, A. 2009. Complete genome sequence of Pirellula staleyi type strain (ATCC 27377(T)). Standards in Genomic Sciences 1(3): 308-316. doi: $10.4056 / \operatorname{sigs} .51657$.

Cole, J.R., Wang, Q., Fish, J.A., Chai, B., McGarrell, D.M., Sun, Y., Brown, C.T., Porras-Alfaro, A., Kuske, C.R., and Tiedje, J.M. 2014. Ribosomal Database Project: data and tools for high throughput rRNA analysis. Nucleic Acids Res. 42(Database issue): D633-642. doi: $10.1093 /$ nar/gkt1244.

Curtis, T.P., and Sloan, W.T. 2004. Prokaryotic diversity and its limits: microbial community structure in nature and implications for microbial ecology. Curr. Opin. Microbiol. 7(3): 221226. doi: 10.1016/j.mib.2004.04.010.

Dailloux, M., Albert, M., Laurain, C., Andolfatto, S., Lozniewski, A., Hartemann, P., and Mathieu, L. 2003. Mycobacterium xenopi and drinking water biofilms. Appl. Environ. Microbiol. 69(11): 6946-6948. 
Delpla, I., Benmarhnia, T., Lebel, A., Levallois, P., and Rodriguez, M.J. 2015. Investigating social inequalities in exposure to drinking water contaminants in rural areas. Environ. Pollut. 207: 88-96. doi: 10.1016/j.envpol.2015.08.046.

Elser, J.J., Bracken, M.E.S., Cleland, E.E., Gruner, D.S., Harpole, W.S., Hillebrand, H., Ngai, J.T., Seabloom, E.W., Shurin, J.B., and Smith, J.E. 2007. Global analysis of nitrogen and phosphorus limitation of primary producers in freshwater, marine and terrestrial ecosystems. Ecol. Lett. 10(12): 1135-1142. doi: 10.1111/j.1461-0248.2007.01113.x.

Ferguson, C., Husman, A.M.D., Altavilla, N., Deere, D., and Ashbolt, N. 2003. Fate and transport of surface water pathogens in watersheds. Crit. Rev. Environ. Sci. Technol. 33(3): 299-361. doi: 10.1080/10643380390814497.

Fierer, N., Bradford, M.A., and Jackson, R.B. 2007. Toward an ecological classification of soil bacteria. Ecology 88(6): 1354-1364. doi: 10.1890/05-1839.

Fish, K.E., Collins, R., Green, N.H., Sharpe, R.L., Douterelo, I., Osborn, A.M., and Boxall, J.B. 2015. Characterisation of the physical composition and microbial community structure of biofilms within a model full-scale drinking water distribution system. PLoS One 10(2): e0115824. doi: 10.1371/journal.pone.0115824.

Glockner, F.O., Zaichikov, E., Belkova, N., Denissova, L., Pernthaler, J., Pernthaler, A., and Amann, R. 2000. Comparative 16S rRNA analysis of lake bacterioplankton reveals globally distributed phylogenetic clusters including an abundant group of actinobacteria. Appl. Environ. Microbiol. 66(11): 5053-+. doi: 10.1128/aem.66.11.5053-5065.2000. 
Gottinger, A.M., McMartin, D.W., Price, D., and Hanson, B. 2011. The effectiveness of slow sand filters to treat Canadian rural prairie water. Canadian Journal of Civil Engineering 38(4): 455-463. doi: 10.1139/111-018.

Gough, R., Cohen, Y., Fenner, N., Cannon, J., and Freeman, C. 2016. Relationships between reservoir water quality and catchment habitat type. International Journal of Environmental Technology and Management 19(1): 16-39. doi: 10.1504/IJETM.2016.074799.

Gu, Q., Wu, Q., Zhang, J., Guo, W., Wu, H., and Sun, M. 2016. Community analysis and recovery of phenol-degrading bacteria from drinking water biofilters. Frontiers in Microbiology 7:495.

Hardie, D., and Alasia, A. 2009. Domestic water use: The relevance of rurality in quantity used and perceived quality In Rural and Small Town Canada Analysis Bulletin Edited by S. Canada.

Harris, J.K., Kelley, S.T., and Pace, N.R. 2004. New perspective on uncultured bacterial phylogenetic division OP11. Appl. Environ. Microbiol. 70(2): 845-849. doi: 10.1128/AEM.70.2.845-849.2004.

Huang, H., Brooks, B.W., Lowman, R., and Carrillo, C.D. 2015. Campylobacter species in animal, food, and environmental sources, and relevant testing programs in Canada. Canadian Journal of Microbiology 61(10): 701-721. doi: 10.1139/cjm-2014-0770.

Huang, S., Vieira, S., Bunk, B., Riedel, T., Sproer, C., and Overmann, J. 2016. First complete genome sequence of a subdivision 6 Acidobacterium strain. Genome Announc 4(3). doi: 10.1128/genomeA.00469-16. 
Jang, M., Chen, W.F., and Cannon, F.S. 2008. Preloading hydrous ferric oxide into granular activated carbon for arsenic removal. Environ. Sci. Technol. 42(9): 3369-3374. doi: $10.1021 /$ es 7025399.

Kaarela, O.E., Harkki, H.A., Palmroth, M.R.T., and Tuhkanen, T.A. 2015. Bacterial diversity and active biomass in full-scale granular activated carbon filters operated at low water temperatures. Environ. Technol. 36(6): 681-692. doi: 10.1080/09593330.2014.958542.

Kim, J., and Kang, B. 2008. DBPs removal in GAC filter-adsorber. Water Res. 42(1-2): 145-152. doi: 10.1016/j.watres.2007.07.040.

Kolpin, D.W., Furlong, E.T., Meyer, M.T., Thurman, E.M., Zaugg, S.D., Barber, L.B., and Buxton, H.T. 2002. Pharmaceuticals, hormones, and other organic wastewater contaminants in US streams, 1999-2000: A national reconnaissance. Environ. Sci. Technol. 36(6): 12021211. doi: $10.1021 / \mathrm{es} 011055 \mathrm{j}$.

Leclerc, H., Schwartzbrod, L., and Dei-Cas, E. 2002. Microbial agents associated with waterborne diseases. Crit. Rev. Microbiol. 28(4): 371-409. doi: 10.1080/1040-840291046768.

Lee, K.C., Herbold, C.W., Dunfield, P.F., Morgan, X.C., McDonald, I.R., and Stott, M.B. 2013. Phylogenetic delineation of the novel phylum Armatimonadetes (former candidate division OP10) and definition of two novel candidate divisions. Appl. Environ. Microbiol. 79(7): 2484-2487. doi: 10.1128/aem.03333-12.

Liao, X., Chen, C., Zhang, J., Dai, Y., Zhang, X., and Xie, S. 2015. Operational performance, biomass and microbial community structure: impacts of backwashing on drinking water biofilter. Environmental Science and Pollution Research International 22(1): 546-554. doi: 10.1007/s11356-014-3393-7. 
Liao, X., Zou, R., Chen, C., Yuan, B., Zhou, Z., Ma, H., and Zhang, X. 2016. Biomass development in GAC columns feeding influents with different level of nutrients. Water Science and Technology: Water Supply.

Lucker, S., Wagner, M., Maixner, F., Pelletier, E., Koch, H., Vacherie, B., Rattei, T., Damste, J.S.S., Spieck, E., Le Paslier, D., and Daims, H. 2010. A Nitrospira metagenome illuminates the physiology and evolution of globally important nitrite-oxidizing bacteria. Proceedings of the National Academy of Sciences of the United States of America 107(30): 13479-13484. doi: $10.1073 /$ pnas. 1003860107.

Lyra, C., Suomalainen, S., Gugger, M., Vezie, C., Sundman, P., Paulin, L., and Sivonen, K. 2001. Molecular characterization of planktic cyanobacteria of Anabaena, Aphanizomenon, Microcystis and Planktothrix genera. Int. J. Syst. Evol. Microbiol. 51(Pt 2): 513-526. doi: $10.1099 / 00207713-51-2-513$.

Maestre, J.P., Wahman, D.G., and Speitel, G.E. 2013. Monochloramine cometabolism by Nitrosomonas europaea under drinking water conditions. Water Res. 47(13): 4701-4709. doi: 10.1016/j.watres.2013.05.019.

Maestre, J.P., Wahman, D.G., and Speitel, G.E. 2016. Monochloramine cometabolism by mixedculture nitrifiers under drinking water conditions. Environ. Sci. Technol. 50(12): 6240-6248. doi: 10.1021/acs.est.5b05641.

McCoy, S.T., and VanBriesen, J.M. 2012. Temporal variability of bacterial diversity in a chlorinated drinking water distribution system. J. Environ. Eng. 138(7): 786-795. doi: doi:10.1061/(ASCE)EE.1943-7870.0000539. 
McLeod, L., Bharadwaj, L., and Waldner, C. 2014. Risk factors associated with the choice to drink bottled water and tap water in rural Saskatchewan. Int. J. Env. Res. Public Health 11(2): 1626-1646. doi: 10.3390/ijerph110201626.

Meyer, F., Paarmann, D., D'Souza, M., Olson, R., Glass, E.M., Kubal, M., Paczian, T., Rodriguez, A., Stevens, R., Wilke, A., Wilkening, J., and Edwards, R.A. 2008. The metagenomics RAST server - a public resource for the automatic phylogenetic and functional analysis of metagenomes. BMC Bioinformatics 9. doi: 10.1186/1471-2105-9-386.

Neilan, B.A., Dittmann, E., Rouhiainen, L., Bass, R.A., Schaub, V., Sivonen, K., and Borner, T. 1999. Nonribosomal peptide synthesis and toxigenicity of cyanobacteria. J. Bacteriol. 181(13): 4089-4097.

Niemi, R.M., Heiskanen, I., Heine, R., and Rapala, J. 2009. Previously uncultured betaProteobacteria dominate in biologically active granular activated carbon (BAC) filters. Water Res. 43(20): 5075-5086. doi: 10.1016/j.watres.2009.08.037.

Niquette, P., Prevost, M., Servais, P., Beaudet, J.F., Coallier, J., and Lafrance, P. 1998. Shutdown of BAC filters: effects on water quality. Journal American Water Works Association 90(12): 53-61.

Parks, D.H., and Beiko, R.G. 2010. Identifying biologically relevant differences between metagenomic communities. Bioinformatics 26(6): 715-721. doi:

10.1093/bioinformatics/btq041.

Pinto, A.J., Schroeder, J., Lunn, M., Sloan, W., and Raskin, L. 2014. Spatial-temporal survey and occupancy-abundance modeling to predict bacterial community dynamics in the drinking water microbiome. Mbio 5(3). doi: 10.1128/mBio.01135-14. 
Pinto, A.J., Xi, C.W., and Raskin, L. 2012. Bacterial community structure in the drinking water microbiome is governed by filtration processes. Environ. Sci. Technol. 46(16): 8851-8859. doi: 10.1021/es302042t.

Rendulic, S., Jagtap, P., Rosinus, A., Eppinger, M., Baar, C., Lanz, C., Keller, H., Lambert, C., Evans, K.J., Goesmann, A., Meyer, F., Sockett, R.E., and Schuster, S.C. 2004. A predator unmasked: Life cycle of Bdellovibrio bacteriovorus from a genomic perspective. Science 303(5658): 689-692. doi: 10.1126/science.1093027.

Revetta, R.P., Gomez-Alvarez, V., Gerke, T.L., Curioso, C., Domingo, J.W.S., and Ashbolt, N.J. 2013. Establishment and early succession of bacterial communities in monochloraminetreated drinking water biofilms. FEMS Microbiol. Ecol. 86(3): 404-414. doi: 10.1111/15746941.12170.

Revetta, R.P., Gomez-Alvarez, V., Gerke, T.L., Domingo, J.W., and Ashbolt, N.J. 2016. Changes in bacterial composition of biofilm in a metropolitan drinking water distribution system. J. Appl. Microbiol. 121(1): 294-305. doi: 10.1111/jam.13150.

Rochex, A., Godon, J.J., Bernet, N., and Escudie, R. 2008. Role of shear stress on composition, diversity and dynamics of biofilm bacterial communities. Water Res. 42(20): 4915-4922. doi: 10.1016/j.watres.2008.09.015.

Sen, K., and Rodgers, M. 2004. Distribution of six virulence factors in Aeromonas species isolated from US drinking water utilities: a PCR identification. J. Appl. Microbiol. 97(5): 1077-1086. doi: 10.1111/j.1365-2672.2004.02398.x.

Shaw, J.L.A., Monis, P., Weyrich, L.S., Sawade, E., Drikas, M., and Cooper, A.J. 2015. Using amplicon sequencing to characterize and monitor bacterial diversity in drinking water 
distribution systems. Appl. Environ. Microbiol. 81(18): 6463-6473. doi: 10.1128/aem.0129715.

Song, A.A., Liu, X., Liu, Y., Lyu, L.H., and Ma, L.M. 2015. Fate of organic pollutants in a fullscale drinking water treatment plant using O-3-BAC. Ozone-Science \& Engineering 37(3): 257-268. doi: 10.1080/01919512.2014.997867.

Srivastava, N.K., and Majumder, C.B. 2008. Novel biofiltration methods for the treatment of heavy metals from industrial wastewater. J. Hazard. Mater. 151(1): 1-8. doi: 10.1016/j.jhazmat.2007.09.101.

Stackelberg, P.E., Gibs, J., Furlong, E.T., Meyer, M.T., Zaugg, S.D., and Lippincott, R.L. 2007. Efficiency of conventional drinking-water-treatment processes in removal of pharmaceuticals and other organic compounds. Sci. Total Environ. 377(2-3): 255-272. doi: 10.1016/j.scitotenv.2007.01.095.

Stanish, L.F., Hull, N.M., Robertson, C.E., Harris, J.K., Stevens, M.J., Spear, J.R., and Pace, N.R. 2016. Factors influencing bacterial diversity and community composition in municipal drinking waters in the Ohio River Basin, USA. PLoS One 11(6). doi: 10.1371/journal.pone.0157966.

Stolp, H., and Starr, M.P. 1963. Bdellovibrio bacteriovorus gen. et sp. n., a predatory, ectoparasitic, and bacteriolytic microorganism. Antonie Van Leeuwenhoek Journal of Microbiology and Serology 29(3): 217-\&. doi: 10.1007/bf02046064.

Strous, M., Pelletier, E., Mangenot, S., Rattei, T., Lehner, A., Taylor, M.W., Horn, M., Daims, H., Bartol-Mavel, D., Wincker, P., Barbe, V., Fonknechten, N., Vallenet, D., Segurens, B., Schenowitz-Truong, C., Medigue, C., Collingro, A., Snel, B., Dutilh, B.E., Op den Camp, 
H.J.M., van der Drift, C., Cirpus, I., van de Pas-Schoonen, K.T., Harhangi, H.R., van Niftrik, L., Schmid, M., Keltjens, J., van de Vossenberg, J., Kartal, B., Meier, H., Frishman, D., Huynen, M.A., Mewes, H.W., Weissenbach, J., Jetten, M.S.M., Wagner, M., and Le Paslier, D. 2006. Deciphering the evolution and metabolism of an anammox bacterium from a community genome. Nature 440(7085): 790-794. doi: 10.1038/nature04647.

Ternes, T.A., Meisenheimer, M., McDowell, D., Sacher, F., Brauch, H.J., Gulde, B.H., Preuss, G., Wilme, U., and Seibert, N.Z. 2002. Removal of pharmaceuticals during drinking water treatment. Environ. Sci. Technol. 36(17): 3855-3863. doi: 10.1021/es015757k.

The World Bank. 2016. Improved water source, rural (\% of rural population with access). Available from http://data.worldbank.org/indicator/SH.H2O.SAFE.RU.ZS [accessed March $282016]$.

Thomas, V., Loret, J.F., Jousset, M., and Greub, G. 2008. Biodiversity of amoebae and amoebaeresisting bacteria in a drinking water treatment plant. Environ. Microbiol. 10(10): 2728-2745. doi: 10.1111/j.1462-2920.2008.01693.x.

Urfer, D., Huck, P.M., Booth, S.D.J., and Coffey, B.M. 1997. Biological filtration for BOM and particle removal: a critical review. Journal American Water Works Association 89(12): 83-98.

van Hannen, E.J., Zwart, G., van Agterveld, M.P., Gons, H.J., Ebert, J., and Laanbroek, H.J. 1999. Changes in bacterial and eukaryotic community structure after mass lysis of filamentous cyanobacteria associated with viruses. Appl. Environ. Microbiol. 65(2): 795-801.

Wagner, D., and Young, L.S. 2004. Nontuberculous mycobacterial infections: A clinical review. Infection 32(5): 257-270. doi: 10.1007/s15010-004-4001-4. 
Wang, H., Pryor, M.A., Edwards, M.A., Falkinham, J.O., and Pruden, A. 2013. Effect of GAC pre-treatment and disinfectant on microbial community structure and opportunistic pathogen occurrence. Water Res. 47(15): 5760-5772. doi: 10.1016/j.watres.2013.06.052.

Wang, Q., Garrity, G.M., Tiedje, J.M., and Cole, J.R. 2007. Naive Bayesian classifier for rapid assignment of rRNA sequences into the new bacterial taxonomy. Appl. Environ. Microbiol. 73(16): 5261-5267. doi: 10.1128/aem.00062-07.

Wilkes, G., Edge, T.A., Gannon, V.P.J., Jokinen, C., Lyautey, E., Neumann, N.F., Ruecker, N., Scott, A., Sunohara, M., Topp, E., and Lapen, D.R. 2011. Associations among pathogenic bacteria, parasites, and environmental and land use factors in multiple mixed-use watersheds. Water Res. 45(18): 5807-5825. doi: 10.1016/j.watres.2011.06.021.

World Health Organization 2011. Guidelines for drinking-water quality. $4^{\text {th }}$ Edition. ISBN: 978 9241548151.

Xiaojian, Z., Zhansheng, W., and Xiasheng, G. 1991. Simple combination of biodegradation and carbon adsorption the mechanism of the biological activated carbon process. Water Res. 25(2): 165-172. doi: 10.1016/0043-1354(91)90025-1.

Yang, Q.X., Jia, Z.J., Liu, R.Y., and Chen, J.J. 2007. Molecular diversity and anammox activity of novel planctomycete-like bacteria in the wastewater treatment system of a full-scale alcohol manufacturing plant. Process Biochem. 42(2): 180-187. doi:

10.1016/j.procbio.2006.07.032.

Yapsakli, K., Mertoglu, B., and Cecen, F. 2010. Identification of nitrifiers and nitrification performance in drinking water biological activated carbon (BAC) filtration. Process Biochem. 45(9): 1543-1549. doi: 10.1016/j.procbio.2010.06.004. 
Zanacic, E., Stavrinides, J., and McMartin, D.W. 2016. Field-analysis of potable water quality and ozone efficiency in ozone-assisted biological filtration systems for surface water treatment. Water Res. 104:397-407. doi: 10.1016/j.watres.2016.08.043.

Zhang, D., Li, W., Zhang, S., Liu, M., Zhao, X., and Zhang, X. 2011. Bacterial community and function of biological activated carbon filter in drinking water treatment. Biomedical and Environmental Sciences 24(2): 122-131. doi: 10.3967/0895-3988.2011.02.006.

Zhang, H., Sekiguchi, Y., Hanada, S., Hugenholtz, P., Kim, H., Kamagata, Y., and Nakamura, K. 2003. Gemmatimonas aurantiaca gen. nov., sp nov., a Gram-negative, aerobic, polyphosphate-accumulating micro-organism, the first cultured representative of the new bacterial phylum Gemmatimonadetes phyl. nov. Int. J. Syst. Evol. Microbiol. 53: 1155-1163. doi: 10.1099/ijs.0.02520-0.

Zhang, P., Lapara, T.M., Goslan, E.H., Xie, Y.F., Parsons, S.A., and Hozalski, R.M. 2009. Biodegradation of haloacetic acids by bacterial isolates and enrichment cultures from drinking water systems. Environ. Sci. Technol. 43(9): 3169-3175. doi: 10.1021/es802990e.

Zhu, I.X., Getting, T.O.M., and Bruce, D.A.N. 2010. Review of biologically active filters in drinking water applications. Journal - American Water Works Association 102(12): 67-77. 
https://mc06.manuscriptcentral.com/cjm-pubs 


\section{Figure Legends}

Figure 1. A. Proportion of classified Bacteria and Archaea in four surface water (raw) samples at Osage and Benson in the fall of 2012 and the spring of 2013, and three biological activated carbon (BAC) samples collected at Osage in the fall of 2012. B. Relative proportion of Bacterial and Archaeal phyla in four surface water samples at Osage and Benson, and three biological activated carbon (BAC) samples collected at Osage. "Others" includes 27 phyla and candidate phyla, most of which had $<1 \%$ relative abundance. C. Proportion of six different classes of Proteobacteria across samples. "Unclassified" sequences could not be assigned to a taxonomic group at an $80 \%$ confidence threshold with the Ribosome Database Project Classifier (Cole et al. 2014; Wang et al. 2007).

Figure 2. Proportion of predominant genera $(>0.3 \%)$ in seasonal samples taken at Osage and Benson. Reads classified to genus level, but which comprised $<0.3 \%$ of diversity are represented in the "other classified" slice. Sequences not classified to genus level at an $80 \%$ confidence threshold are represented by the "unclassified" slice. Asterisks indicate candidatus or incertae sedis status.

Figure 3. A. Comparison of the proportions of the Proteobacteria, Actinobacteria, and Verrucomicrobia between seasons within each site. B. Comparison of the proportions of the Proteobacteria, Bacteroidetes, and Cyanobacteria between Osage and Benson for each season. C. Summary of the phyla that show temporal (season-specific) and spatial (site-specific) increases in their relative proportions at Osage and Benson. D. Phyla that exhibit significant changes in relative proportion between the Osage raw water and the Osage BAC filter (top 
fraction). Two-sample comparisons were carried out using two-sided G-test (with Yates') + Fisher's and Storey-FDR multiple-test correction. All unclassified sequences were retained for these analyses. ${ }^{*} \mathrm{p}<0.02 ; * * 10^{-3}>\mathrm{p}>10^{-12} ; * * * \mathrm{p}<10^{-12}$.

Figure 4. Relative abundance of Legionella, Pseudomonas, Aeromonas and Mycobacterium from Osage raw water (Raw), through the different biological activated carbon (BAC) filter layers (top, middle, bottom). 
Table 1. Relative abundance of predominant genera in Osage raw water relative to the different layers of the biological activated carbon (BAC) filter.

Phylum
Nitrospirae
Acidobacteria
Planctomycetes
Gemmatimonadetes
Verrucomicrobia
Armatimonadetes
Proteobacteria
Candidatus Saccharibacteria
Acidobacteria
Proteobacteria
Proteobacteria
Verrucomicrobia
Proteobacteria
Acidobacteria
Acidobacteria
Proteobacteria
Acidobacteria
candidate division WPS-1
Chloroflexi
Proteobacteria
Actinobacteria
Acidobacteria
Pacearchaeota
Acidobacteria
Actinobacteria
Armatimonadetes
Verrucomicrobia
Proteobacteria
Bacteroidetes
Bacteroidetes
Verrucomicrobia
Cyanobacteria
(Chloroplast)
Cyanobacteria
Proteobacteria
(Chloroplast)
(Chloroplast)
Asteistindits inertaesedis

Phylum

Nitrospirae

Acidobacteria

Planctomycetes

Gemmatimonadetes

Armatimonadetes

Proteobacteria

Candidatus Saccharibacteria

Acidobacteria

Proteobacteria

Verrucomicrobia

Acidobacteria

Acidobacteria

Proteobacteria

Acidobacteria

candidate division WPS-1

Chloroflexi

Actinobacteria

Acidobacteria

\# Asterisk indicates incertae sedis
${ }^{\#}$ Genus

Nitrospira

Group 6

Pirellula

Gemmatimonas

Subdivision3*

Group 5

Arenimonas

Saccharibacteria*

Group 16

Thiothrix

Thiobacillus

Spartobacteria*

Bdellovibrio

Group 10

Group 4

Aquicella

Group 3

WPS-1*

Litorilinea

Nitrosomonas

Gaiella

Group 7

Pacearchaeota (AR13)*

Aridibacter

Mycobacterium

Armatimonas (Group I)

Luteolibacter

Rheinheimera

Fluviicola

Flavobacterium

Opitutus

Group IIa

Chlorophyta

Group I

Polynucleobacter

Cryptomonadaceae

Bacillariophyta

\begin{tabular}{|c|c|c|c|}
\hline & \multicolumn{3}{c}{ BAC FILTER } \\
\hline Raw & Top & Middle & Bottom \\
\hline $1.1 \%$ & $5.5 \%$ & $5.0 \%$ & $6.7 \%$ \\
\hline $0.9 \%$ & $2.4 \%$ & $3.1 \%$ & $4.2 \%$ \\
\hline $0.6 \%$ & $2.4 \%$ & $2.8 \%$ & $3.2 \%$ \\
\hline $1.3 \%$ & $1.1 \%$ & $0.8 \%$ & $1.1 \%$ \\
\hline $0.4 \%$ & $0.6 \%$ & $0.7 \%$ & $0.5 \%$ \\
\hline $0.3 \%$ & $0.6 \%$ & $0.6 \%$ & $0.6 \%$ \\
\hline $0.6 \%$ & $0.6 \%$ & $0.4 \%$ & $0.3 \%$ \\
\hline $0.3 \%$ & $0.3 \%$ & $0.4 \%$ & $0.4 \%$ \\
\hline $0.2 \%$ & $0.5 \%$ & $0.8 \%$ & $0.6 \%$ \\
\hline $0.0 \%$ & $0.7 \%$ & $0.4 \%$ & $0.6 \%$ \\
\hline $0.2 \%$ & $0.6 \%$ & $0.4 \%$ & $0.4 \%$ \\
\hline $0.1 \%$ & $0.4 \%$ & $0.5 \%$ & $0.4 \%$ \\
\hline $0.2 \%$ & $0.4 \%$ & $0.4 \%$ & $0.4 \%$ \\
\hline $0.1 \%$ & $0.3 \%$ & $0.4 \%$ & $0.4 \%$ \\
\hline $0.1 \%$ & $0.3 \%$ & $0.3 \%$ & $0.4 \%$ \\
\hline $0.0 \%$ & $0.4 \%$ & $0.3 \%$ & $0.3 \%$ \\
\hline $0.1 \%$ & $0.3 \%$ & $0.4 \%$ & $0.3 \%$ \\
\hline $0.0 \%$ & $0.3 \%$ & $0.3 \%$ & $0.3 \%$ \\
\hline $0.1 \%$ & $0.2 \%$ & $0.3 \%$ & $0.4 \%$ \\
\hline $0.0 \%$ & $0.2 \%$ & $0.3 \%$ & $0.3 \%$ \\
\hline $0.0 \%$ & $0.4 \%$ & $0.2 \%$ & $0.5 \%$ \\
\hline $0.2 \%$ & $0.4 \%$ & $0.2 \%$ & $0.3 \%$ \\
\hline $0.1 \%$ & $0.4 \%$ & $0.2 \%$ & $0.3 \%$ \\
\hline $0.1 \%$ & $0.3 \%$ & $0.3 \%$ & $0.2 \%$ \\
\hline $0.2 \%$ & $0.2 \%$ & $0.3 \%$ & $0.2 \%$ \\
\hline $0.3 \%$ & $0.0 \%$ & $0.0 \%$ & $0.0 \%$ \\
\hline $0.3 \%$ & $0.1 \%$ & $0.1 \%$ & $0.1 \%$ \\
\hline $0.4 \%$ & $0.1 \%$ & $0.2 \%$ & $0.1 \%$ \\
\hline $0.5 \%$ & $0.1 \%$ & $0.1 \%$ & $0.1 \%$ \\
\hline $0.6 \%$ & $0.1 \%$ & $0.1 \%$ & $0.1 \%$ \\
\hline $0.7 \%$ & $0.3 \%$ & $0.3 \%$ & $0.3 \%$ \\
\hline $0.7 \%$ & $0.0 \%$ & $0.0 \%$ & $0.1 \%$ \\
\hline $1.0 \%$ & $0.1 \%$ & $0.1 \%$ & $0.1 \%$ \\
\hline $1.4 \%$ & $0.2 \%$ & $0.2 \%$ & $0.1 \%$ \\
\hline $1.5 \%$ & $0.4 \%$ & $0.4 \%$ & $0.2 \%$ \\
\hline $3.8 \%$ & $0.2 \%$ & $0.3 \%$ & $0.2 \%$ \\
\hline $9.0 \%$ & $0.6 \%$ & $0.7 \%$ & $0.5 \%$ \\
\hline & & & \\
\hline
\end{tabular}


A.

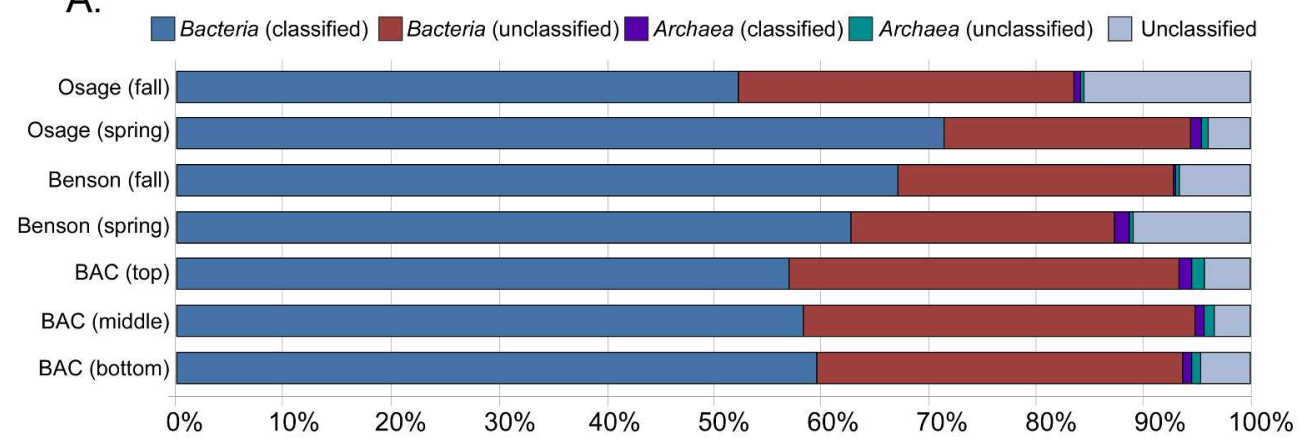

B.

$\square$ Proteobacteria $\square$ Cyanobacteria $\square$ Bacteroidetes $\square$ Planctomycetes $\square$ Acidobacteria $\square$ Actinobacteria $\square$ Verrucomicrobia $\square$ Nitrospirae $\square$ Chloroflexi $\square$ Gemmatimonadetes $\square$ Others $\square$ Unclassified (to phylum)

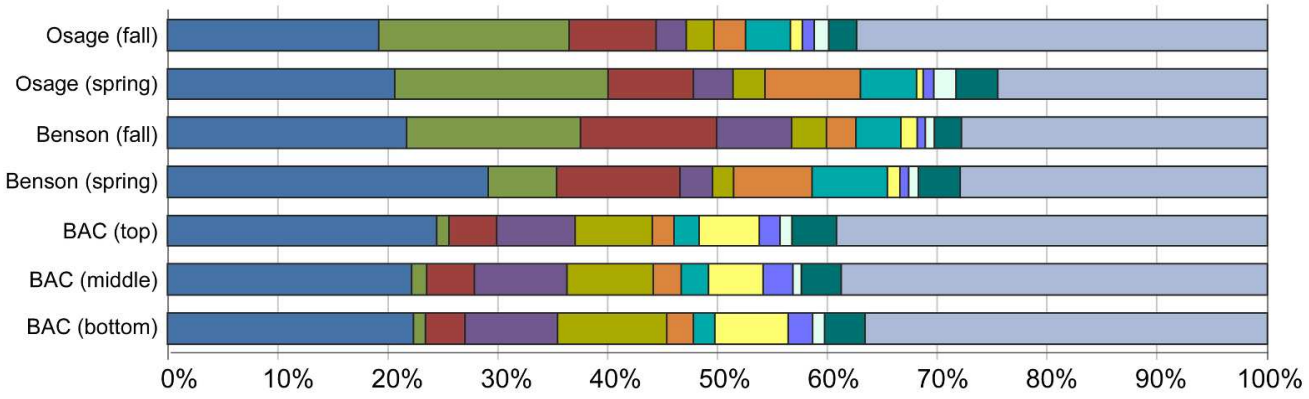

C.

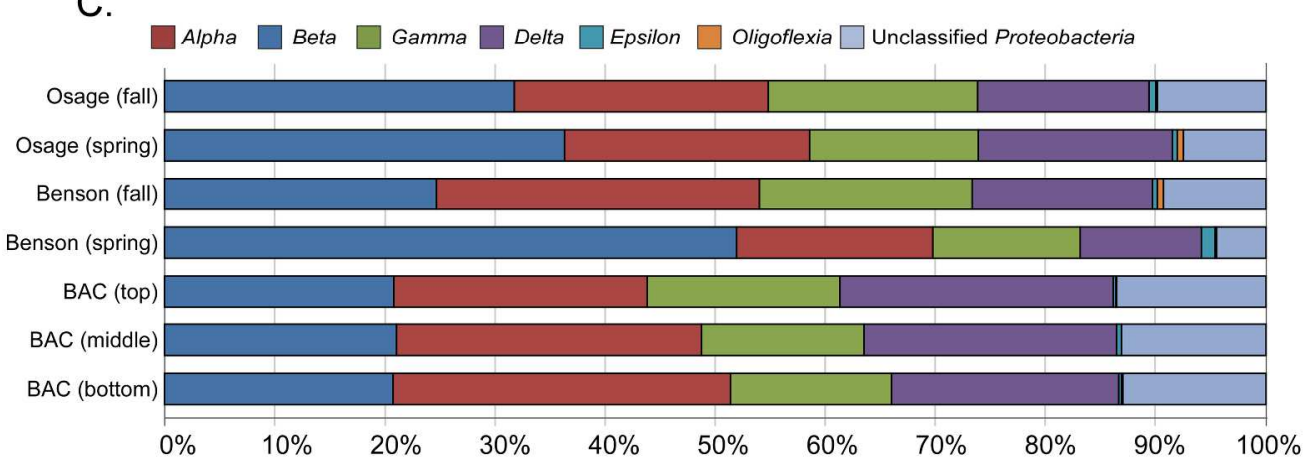

Figure 1

$251 \times 296 \mathrm{~mm}(300 \times 300 \mathrm{DPI})$ 

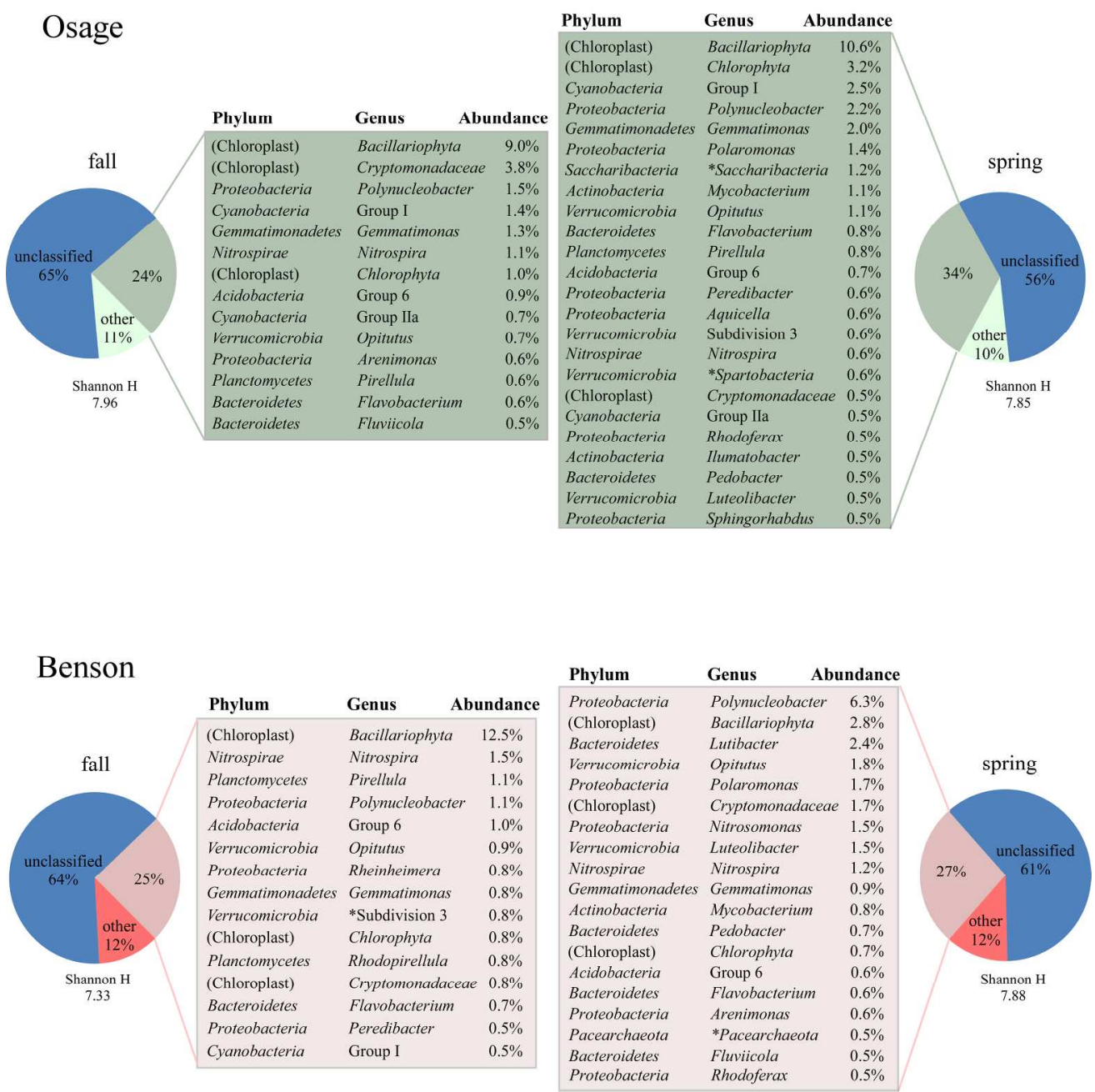

Figure 2

$209 \times 208 \mathrm{~mm}(300 \times 300$ DPI $)$ 
A.

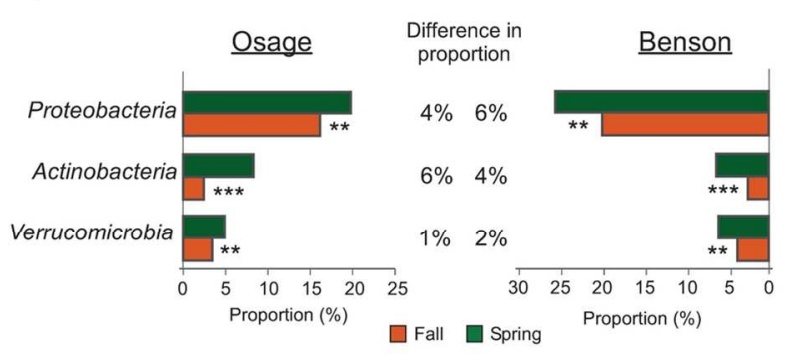

B.

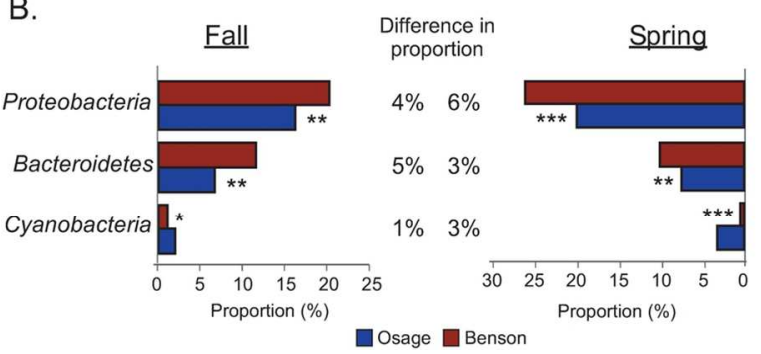

C.

\begin{tabular}{|c|c|c|}
\hline & OSAGE & BENSON \\
\hline SPATIAL & Cyanobacteria & $\begin{array}{l}\text { Bacteroidetes } \\
\text { Proteobacteria }\end{array}$ \\
\hline TEMPORAL & \multicolumn{2}{|c|}{$\begin{array}{c}\text { Proteobacteria } \\
\text { Actinobacteria } \\
\text { Verrucomicrobia }\end{array}$} \\
\hline
\end{tabular}

D.

Difference in

Proteobacteria $\begin{array}{r}* * * \\ \quad 7 \%\end{array}$

Planctomycetes $5 \%$

Acidobacteria $\quad 5 \%$

Nitrospirae $\quad 4 \%$

Chloroflexi ${ }^{* *} \quad 1 \%$

(Chloroplast) $\quad 11 \%$

Bacteroidetes $\quad 3 \%$

Verrucomicrobia $\sigma_{* *} \quad 1 \%$

Cyanobacteria $\overrightarrow{F * * *}_{*}$

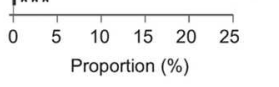

$\square$ Raw $\square$ BAC Filter (Top)

Figure 3

$122 \times 75 \mathrm{~mm}(300 \times 300$ DPI $)$ 


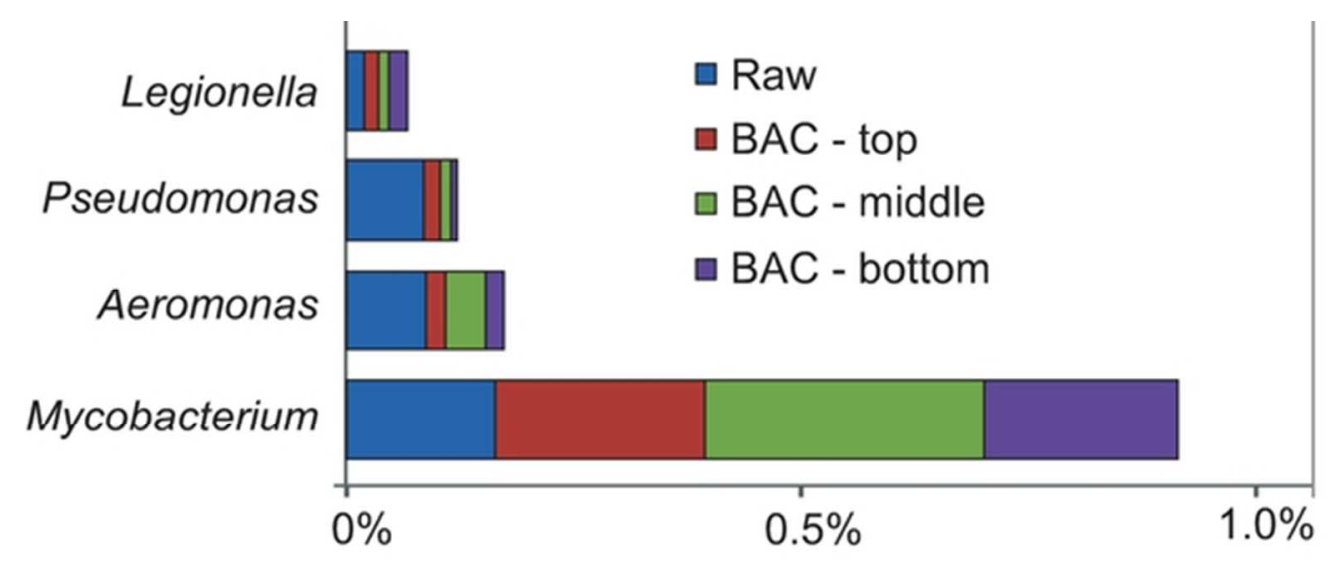

Figure 4

$52 \times 21 \mathrm{~mm}(300 \times 300$ DPI $)$ 


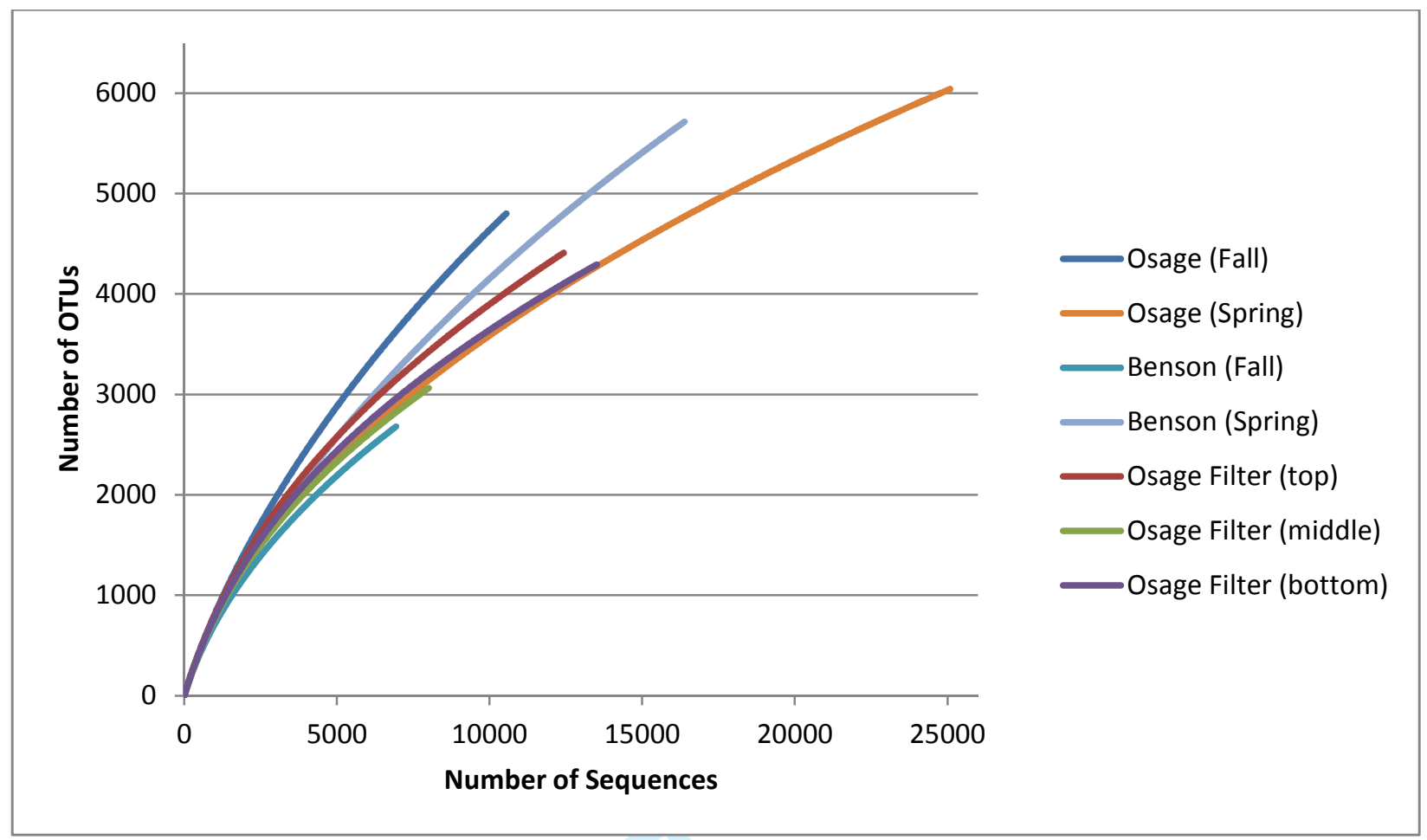

Figure S1. Rarefaction curves of 16 S rRNA sequences for raw water and filter samples at the $97 \%$ sequence similarity cut-off. 


\section{Supplemental Table}

Table S1. Statistical overview of datasets.

\begin{tabular}{|c|c|c|c|c|c|c|c|}
\hline Location & Season & Sample & *Sequences & $* *$ OTUs & $\begin{array}{c}* * * \text { Corrected } \\
\text { Sequence \# }\end{array}$ & $\begin{array}{c}* * \text { Shannon } \\
\text { Index }(\mathbf{H})\end{array}$ & $\begin{array}{l}\text { MG-RAST } \\
\text { Accession }\end{array}$ \\
\hline \multirow[t]{5}{*}{ Osage } & fall & raw (intake) & 10557 & 4803 & 4802 & 7.96236 & 4528546 \\
\hline & spring & raw (intake) & 25099 & 6042 & 11226 & 7.84606 & 4528553 \\
\hline & fall & filter, biological activated carbon, top $1 / 3$ & 12436 & 4411 & 5806 & 7.88273 & 4528547 \\
\hline & fall & filter, biological activated carbon, mid 1/3 & 8016 & 3065 & 3720 & 7.57846 & 4528548 \\
\hline & fall & filter, biological activated carbon, bottom $1 / 3$ & 13516 & 4294 & 6456 & 7.79999 & 4528549 \\
\hline \multirow[t]{2}{*}{ Benson } & fall & raw (intake) & 6941 & 2680 & 3002 & 7.32593 & 4528550 \\
\hline & spring & raw (intake) & 16396 & 5717 & 7515 & 7.87802 & 4528554 \\
\hline
\end{tabular}

*Sequence number after quality control and dereplication . **OTUs and Shannon Index calculated at a distance of 0.03 .

***Sequence number corrected for 16S rRNA copy number, as implemented by RDP. 